\title{
Molecular Characterization, Gene Evolution and Expression Analysis of the F-Box Gene Family in Tomato (Solanum lycopersicum)
}

\author{
Fulei Mo ${ }^{1} \mathbb{1}$, Nian Zhang ${ }^{2}$, Youwen Qiu ${ }^{1}$, Lingjun Meng ${ }^{2}$, Mozhen Cheng ${ }^{1}$, Jiayin Liu ${ }^{3}$, Lanning Yao ${ }^{3}$, Rui Lv ${ }^{2}$, \\ Yuxin Liu ${ }^{2}$, Yao Zhang ${ }^{1}$, Xiuling Chen ${ }^{2, *}$ and Aoxue Wang ${ }^{1,2, *(1)}$ \\ 1 College of Life Science, Northeast Agricultural University, Harbin 150030, China; neaumfl@163.com (F.M.); \\ yw12_630@126.com (Y.Q.); neaucmz@163.com (M.C.); zy13263696020@163.com (Y.Z.) \\ 2 College of Horticulture and Landscape Architecture, Northeast Agricultural University, \\ Harbin 150030, China; neauzn@163.com (N.Z.); neaumlj@163.com (L.M.); lvrui34324080@163.com (R.L.); \\ yuxinliu1223@163.com (Y.L.) \\ 3 College of Arts and Sciences, Northeast Agricultural University, Harbin 150030, China; \\ 13040216@163.com (J.L.); yaoln888@163.com (L.Y.) \\ * Correspondence: chenx@neau.edu.cn (X.C.); axwang@neau.edu.cn (A.W.)
}

check for updates

Citation: Mo, F.; Zhang, N.; Qiu, Y.; Meng, L.; Cheng, M.; Liu, J.; Yao, L.; Lv, R.; Liu, Y.; Zhang, Y.; et al. Molecular Characterization, Gene Evolution and Expression Analysis of the F-Box Gene Family in Tomato (Solanum lycopersicum). Genes 2021, 12, 417. https://doi.org/10.3390/ genes12030417

Academic Editor: Antonio Granell

Received: 22 February 2021

Accepted: 9 March 2021

Published: 14 March 2021

Publisher's Note: MDPI stays neutral with regard to jurisdictional claims in published maps and institutional affiliations.

Copyright: (c) 2021 by the authors. Licensee MDPI, Basel, Switzerland. This article is an open access article distributed under the terms and conditions of the Creative Commons Attribution (CC BY) license (https:/ / creativecommons.org/licenses/by/ $4.0 /)$.

\begin{abstract}
F-box genes play an important role in the growth and development of plants, but there are few studies on its role in a plant's response to abiotic stresses. In order to further study the functions of F-box genes in tomato (Solanum lycopersicum, Sl), a total of 139 F-box genes were identified in the whole genome of tomato using bioinformatics methods, and the basic information, transcript structure, conserved motif, cis-elements, chromosomal location, gene evolution, phylogenetic relationship, expression patterns and the expression under cold stress, drought stress, jasmonic acid (JA) treatment and salicylic acid (SA) treatment were analyzed. The results showed that SIFBX genes were distributed on 12 chromosomes of tomato and were prone to TD (tandem duplication) at the ends of chromosomes. WGD (whole genome duplication), TD, PD (proximal duplication) and TRD (transposed duplication) modes seem play an important role in the expansion and evolution of tomato SIFBX genes. The most recent divergence occurred 1.3042 million years ago, between SIFBX89 and SIFBX103. The cis-elements in SIFBX genes' promoter regions were mainly responded to phytohormone and abiotic stress. Expression analysis based on transcriptome data and qRT-PCR (Real-time quantitative PCR) analysis of SIFBX genes showed that most SIFBX genes were differentially expressed under abiotic stress. SIFBX24 was significantly up-regulated at $12 \mathrm{~h}$ under cold stress. This study reported the SIFBX gene family of tomato for the first time, providing a theoretical basis for the detailed study of SIFBX genes in the future, especially the function of SIFBX genes under abiotic stress.
\end{abstract}

Keywords: abiotic stresses; cis-elements; expression analysis; F-box; gene evolution; tomato

\section{Background}

The F-box gene family is one of the most abundant and versatile families in plants. [1,2]. In the process of biological development and evolution, organisms have possessed many kinds of regulatory mechanisms to respond to external environmental stimuli. Among them, the physiological processes regulated by the F-box gene family are particularly important. In the entire F-box protein family, the sequence of containing F-box plays an irreplaceable role in the plant's growth and development [3-7]. The F-box protein family is very large, meanwhile their functions are also diverse. They are mainly distributed in eukaryotes which main take part in the protein degradation in eukaryotes. The process of F-box degradation of most foreign proteins is mainly through the ubiquitin-proteasome pathway (UPP). The ubiquitin-proteasome system is responsible for removing most abnormal peptides and short-lived cell regulators, thereby regulating many stress response 
processes [8]. The ubiquitin-proteasome system is an important post-translational regulation mechanism. the main proteolytic mechanism in eukaryotes is through this pathway [9]. Cells use this process to quickly respond the changes in intracellular signals and environmental stimuli. There are many unfavorable external environmental conditions affect the plant growth and development, such as drought, salinity, heavy metal stress, and cold [10]. In the study of Arabidopsis thaliana, a model plant and some other plants, it was found that the F-box gene family belongs to one of the most polymorphic supergene families, and their important role permeates almost every plant life cycle [11]. Therefore, the F-box protein plays a key role in the growth and development of plants and the regulatory response to the living environment and endogenous signals.

The F-box was first discovered at the N-terminus of cyclin F [12]. F-box mostly functions as the SCF (SKP1-Cullin-F-box) complex. F-box contains a domain (containing about 40-50 amino acids) at the N-terminus, which is used to bind other components of the SCF complex [13]. The C-terminus is a highly variable domain (protein-protein interaction site), including LRR (Leucine rich repeats), Kelch, and WD40 [13,14]. The SCF complex consists of four subunits. The three subunits Cullinl/Cdc53, Rbxl/Rocl/Hrtl, and Skp1 together form a skeleton, which can specifically bind to different F-box proteins. Then the complex protein could recognize different substrates. Therefore, the F-box protein determines the specificity of substrate recognition in the recognition process [15-17]. According to the analysis of its gene structure, the number of exons and introns in the F-box genes are high variability, which just shows that these genes in plants are extraordinary. Generally speaking, the same type (not exactly the same substrate) can accept the regulation of some F-box genes with highly similar structure. Some F-box proteins may have highly similar functions. Most F-box genes in plants are involved in the regulation of many biological processes, allowing cells to quickly respond to changes in intracellular and extracellular signals and the continuous changes in the living environment. So the structure and function of F-box proteins research is necessary [8].

In earlier studies, Arabidopsis is an important plant carrier for scientists to obtain a lot of information about F-box genes. In plants, only 23 F-box proteins (18 of which are from Arabidopsis) are known for their functions and widely used in research. Some abiotic stresses such as cold, drought and salinity are important restrictive factors that affect plant growth and development $[13,14]$. Therefore, in order to keep normal physiological activities, plants must adapt to or resist these adversities at different physiological and molecular levels. The F-box protein encoding gene family plays a very important role in plant stress resistance. In recent years, many studies on F-box protein's involvement in plant stress response have surfaced [18]. There are more than 43 different types of F-box proteins in monocot rice that can cope with different types of environmental stress, and through repeated database searches, 687 potential F-box proteins have been identified [19]. Most of them may play a positive regulatory role in adversity. Others, including Piper nigrum, Phaseolus vulgaris and Triticum aestivum, have similar expression results [20-22].

When the plants are exposed to abiotic stress, a series of morphological, physiological and biochemical changes will occur, such as slow growth, chlorophyll reduction and even flower and fruit drop, which will lead to crop failure. Cold and drought are two of the main abiotic stress factors, which seriously affect plant growth and production. In order to resist cold or drought damage, it is possible to cultivate abiotic-resistant and plant types. Cold and drought resistance are affected by multiple genes location. Therefore, it is necessary to dig out more genes related to abiotic resistance. In order to have better understanding of the mechanism of abiotic stress response, we focused on the F-box protein. F-box protein is mainly involved in the abiotic stress response of plants. The F-box genes of many miRNAs involved in the regulation of Arabidopsis growth and development may respond to cold and drought. Under low temperature stress, the expression of miR393, $m i R 397 b$ and miR402 were increased, but the translation process of its target gene (putative F-box protein) is reduced. So the growth rate of plants is slowed down, which can improve the cold resistance of plants [23]. MAIF1 is an F-box gene in rice that regulates MiRNAs and 
abiotic stress. Studies have shown that MAIF1 participates in a variety of signal pathways to regulate the growth and development of rice roots. The gene MAIF1 mainly through increasing the number of root cell divisions to establish rice abiotic stresses tolerance (such as chilling injury) [24]. SlEBF3, a new F-box gene in tomato, participates in affecting fruit ripening by interacting with the EIL (Ethylene-insensitive) protein in tomato and mediating its degradation [25] Another F-box gene, ACIF1, has been reported to have a positive regulatory effect on the Ve1-mediated response of verticillium dahliae and white rot of tomato [26]. These results are dedicated to provide useful information for further research on the role of F-box genes in plant abiotic resistance. This study identified the F-box gene family in tomato, and analyzed the molecular characterization, gene evolution, conserved motif and promoter regions. In addition, this study have analyzed the expression patterns based on the transcriptome data, and ten SIFBX genes were selected to validated the transcriptome's result by qRT-PCR. The study will provide a theoretical reference for the research of F-box genes on plant abiotic resistance.

\section{Materials and Methods}

\subsection{Plant Materials and Treatment}

The tomato variety Glamour was planted in the growth chamber of the Northeast Agricultural University, with a light intensity of $120 \mu \mathrm{M}$ photons $\mathrm{m}^{-2} \mathrm{~s}^{-1}$, photoperiod $16 \mathrm{~h}$, day /night temperature $22 / 18{ }^{\circ} \mathrm{C}$, stress treatment with cold and drought, the methods for stress treatment are shown in Zhou et al. [27], $100 \mathrm{mM}$ salicylic acid (SA) and jasmonic acid (JA) were used to treat the 27-day-old plants, each solution was sprayed evenly over each blade and stop spraying before the solution drips from the leaf. The first fully expanded leaf from the top of the plants was collected with three replicates after $0 \mathrm{~h}, 6 \mathrm{~h}, 12 \mathrm{~h}, 24 \mathrm{~h}$, $36 \mathrm{~h}$ and $48 \mathrm{~h}$ per treatment [27]. Three plants of the same growth were selected for each treatment as three biological replicates, and then three technical replicates were performed for each biological replicate.

\subsection{Identification the Members of SIFBX Gene Family in Tomato}

The Hidden Markov Model (HMM) of F-box domain (PF00646) was downloaded from the Pfam database (http:/ / pfam.xfam.org, 1 December 2020). The DNA sequence, CDS (Coding DNA Sequence) file, total proteins sequence and the gff3 file were downloaded from the Ensembl Plants database (1 December 2020, http:/ / plants.ensembl.org) and the genome annotation version is SL3.0. Using the hmmsearch tool from HMMER v3.0 to search domains similar to F-box domain in the total protein sequences of tomato [28], and set the value to $1 \times 10^{-5}$. Then filtering the result with the cutoff value was set to 0.001. Besides, the full-length protein sequences were submitted to the Pfam, SMART (http: / / smart.embl-heidelberg.de, 1 December 2020, and CDD (Conserved Domains Database, 1 December 2020, https:/ / www.ncbi.nlm.nih.gov/Structure/cdd/cdd.shtml) databases to confirm the candidate genes contain the F-box domain.

\subsection{Sequence Analysis of SlFBX Genes in Tomato}

The length, isoelectric point, and molecular weight of SIFBX protein sequences were analyzed by Bioperl and the ExPasy website (1 December 2020, https:/ / www.expasy.org). The MEME-v4.12.0 software was used to identify the motif of SIFBX protein sequences [29], the main options of MEME software is followed: sequence use protein alphabet; maximum number of motifs to find was 10; the minimum and maximum motif width were 6 and 20 . The gene structures were extracted from the gff 3 file, then use the TBtools to statistics and visualize the motifs and exon-intron and UTR (Untranslated Region) regions. In order to identify the type of cis-elements in the promoter from SIFBX genes, $1500 \mathrm{bp}$ of the genomics sequence upstream of the transcriptional start site was submitted to the PlantCARE website (1 December 2020, http:/ /bioinformatics.psb.ugent.be/webtools/plantcare/html). 


\subsection{Phylogenetic Analysis and Chromosomal Location}

The full-length sequence of certain members in SIFBX gene family from tomato was alignment by MUSCLE in MEGA version 7 software [30]. Build a neighbor joining tree with the bootstrapping was performed with 1000, the other parameters are default values. The location of all SIFBX genes and the length of chromosome were obtained from Ensembl Plants database and mapped by the TBtools [31]. In addition, in order to study the evolutionary relationship between SIFBX gene and other species, F-box genes in Nicotiana attenuata (NIATTr2), Solanum tuberosum (SolTub_3.0) and Coffea canephora (AUK_PRJEB4211_v1) were identified by the method in Section 2.2, and the evolutionary tree was drawn, and use iTOL (1 December 2020, https:/ / itol.embl.de) for beautification. The genomes and protein sequences of these three species were download from Ensemble plants database.

\subsection{Duplication, Ka/Ks and Synteny Analysis}

Synonymous substitution rate (Ks) and nonsynonymous substitution rate (Ka) can reflects the evolutionary relationship between genes [32]. The blastall tool was used to blast the CDS sequences of 139 SlFBX genes, and the expectation value is 1e-20, the other parameters are default values [33]. Then faidx the result from blastall by samtools, and filtered the result used for calculate $\mathrm{Ka} / \mathrm{Ks}$ value by a perl script. The criteria for filtering were as follows: the length of aligned genes was greater than $70 \%$ of the longer gene, and the similarity between the two genes was greater than $70 \%$; the distance between the two genes was less than $100 \mathrm{~kb}$ [34]. Calculating the value of Ka and Ks with KaKs_calculator [35]. The formula $\mathrm{T}=\mathrm{Ks} / \mathrm{r}$ was used to calculate the divergence time, with $\mathrm{r}$ being the rate of divergence for nuclear genes from plants. For dicotyledonous plants the $r$ was taken to be $1.5 \times 10^{-8}$ synonymous substitutions per site per year [36].

Genes duplication and synteny were analyzed by MCScanX-transposed [37], the main option of is followed: MATCH_SCORE: 50, MATCH_SCORE: -1, MATCH_SIZE: 5, E_VALUE: $1 \times 10^{-5}$. The inhouse script duplicate_gene_classifier was used to classify all pairs of SIFBX genes in tomato, including segmental, tandem, proximal, and dispersed duplications under the default criteria. Circos software was used to visualize collinear regions and members of gene families in the genome [38].

\subsection{Expression Analysis Based on RNA-Seq}

In order to research the expression patterns of SIFBX genes in tomato, the RNAseq data were downloaded from NCBI (National Center for Biotechnology Information) database with under the accession number of SRP156535 at https: / www.ncbi.nlm.nih. gov /sra/SRP156535 (1 December 2020). Control (SRR7652565, SRR7652566, SRR7652567), use cold instead of low temperature (SRR7652564, SRR7652570, SRR7652571), drought (SRR7652563, SRR7652568, SRR7652569). HISAT software was used to map the reads from all samples to the tomato genome [39]. The featurecounts tool of Rsubread package in $R$ was used to the genes quantification [40] and visualized by TBtools.

\subsection{RNA Extraction and Real-Time PCR Validation}

Total RNA was extracted from the tomato leaves with plant RNA mini kit (Watson, China) and reverse transcribed to cDNA with the TransScript One-Step gDNA Removal and cDNA Synthesis SuperMix Kit (Applied Biosystems, Shanghai, China). Two genes were selected from each subtribe, a total of ten genes from SIFBX genes were selected to validate the accuracy of the RNA-Seq data. The primers as shown in Supplementary Table S1, were designed on NCBI and used for qRT-PCR. Each reaction contains $10 \mu \mathrm{L}$ Unique AptamerTM qPCR SYBR Green Master Mix (Applied Biosystems, Shanghai, China), $0.4 \mu \mathrm{L}$ forward primer $(10 \mu \mathrm{M}), 0.4 \mu \mathrm{L}$ reverse primer $(10 \mu \mathrm{M})$, and $1.0 \mu \mathrm{L}$ of diluted cDNA sample. Finally, add sterile ultrapure water to replenish to $20 \mu \mathrm{L}$. The polymerase chain reaction (PCR) conditions were as follows: initial denaturation at $95^{\circ} \mathrm{C}$ for $5 \mathrm{~min}$ followed by 40 cycles of denaturation at $95{ }^{\circ} \mathrm{C}$ for $10 \mathrm{~s}, 60{ }^{\circ} \mathrm{C}$ for $20 \mathrm{~s}$ and $72{ }^{\circ} \mathrm{C}$ for 
$20 \mathrm{~s}$. The relative expression level was calculated using the $2^{-\Delta \Delta c t}$ method [41]. The actin gene was employed as a standardized internal control, and the relative mRNA levels in untreated normal plants were normalized to 3 biological replicates were employed for each sample. qRT-PCR data were analyzed by SPSS software (1 December 2020, https://www.ibm.com/cn-zh/analytics/spss-statistics-software).

\section{Results}

\subsection{Identification of F-Box Genes in the Tomato Genome}

A total of 166 putative F-Box genes were identified in the tomato genome by using HMMER software. In order to identify whether those genes contain F-Box domain, the proteins' sequence of the putative F-Box genes were submitted to SMART, Pfam and CDD three databases. After removing the redundant sequences without an F-box domain, a total of 139 genes were obtained for subsequent study. They are named SIFBX1 to SlFBX139 according to the chromosomal location of the genes. Supplementary Table S2 shows the genes' name, genes' id, genes' location, coding amino acid lengths, and isoelectric points (pI) of the 139 tomato SIFBX genes. As shown in Supplementary Table S2, the amino acid length of its coding protein is between 35 (SIFBX50) and 1662 (SIFBX117). Isoelectric points of those proteins ranged from 4.16 (SIFBX105) to 10.38 (SIFBX12). SIFBX have a wide range of molecular weights from 4079.9 Da (SIFBX50) to 189118.1 Da (SIFBX117). The results showed that the SIFBX gene family had many members, and the differences among the members, such as the length of the coding amino acid, isoelectric point and molecular weight, were all significantly different.

\subsection{Motifs Identification and Gene Structure Analysis of SlFBX Gene Family}

In order to determine whether the structure and conserved motifs of SlFBX genes are related to phylogeny, 139 SlFBX gene protein sequences were submitted to MEGAX software for analysis and used the MEME tool for conservative motif analysis. In addition, the extracted structural information of SIFBX gene family members was from tomato genome annotation files. Finally, we used the TBtools for visualization. Phylogenetic tree, motifs, and gene structures were shown as in Figure 1, respectively.

As shown in Figure 1, to clarify the phylogenetic relationship of SlFBX genes in tomato, 139 SIFBX genes were divided into 5 subtribes A-E after analysis by MEGA7.0 software, which contained $43,10,34,36$ and 16 SIFBX family members respectively and the evolutionary relationship of SIFBX genes was demonstrated.

There were 10 kinds of motifs with high confidence identified from SlFBX gene family, but about $7.9 \%(11 / 139)$ of the genes could not identify them, probably because the E-value of these 11 SIFBX genes were greater than that of other motifs. The sequences logos of all motifs are shown in Figure S1. Motif 1 appeared nearly 77\% (107/139) of the time in all protein sequences, making it the most frequent motif of all motifs. There is a high correlation between the distribution of motif and phylogeny. For example, in subtribe A, motif 1 and 9 always appeared together, and motif 2, 3,5 and 10 always seemed to appear together in subtribe B. Most of motif 4 are concentrated in subtribe $C$, and in subtribe $C$, SIFBX75 was the most motif 4 containing protein, and there were 16 motif 4 in SIFBX75.

However, the result show that there was no significant correlation between gene structure and phylogenetic relationship, and the distribution of introns from 1 (such as SlFBX49) to 24 (SlFBX117) was irregular. 


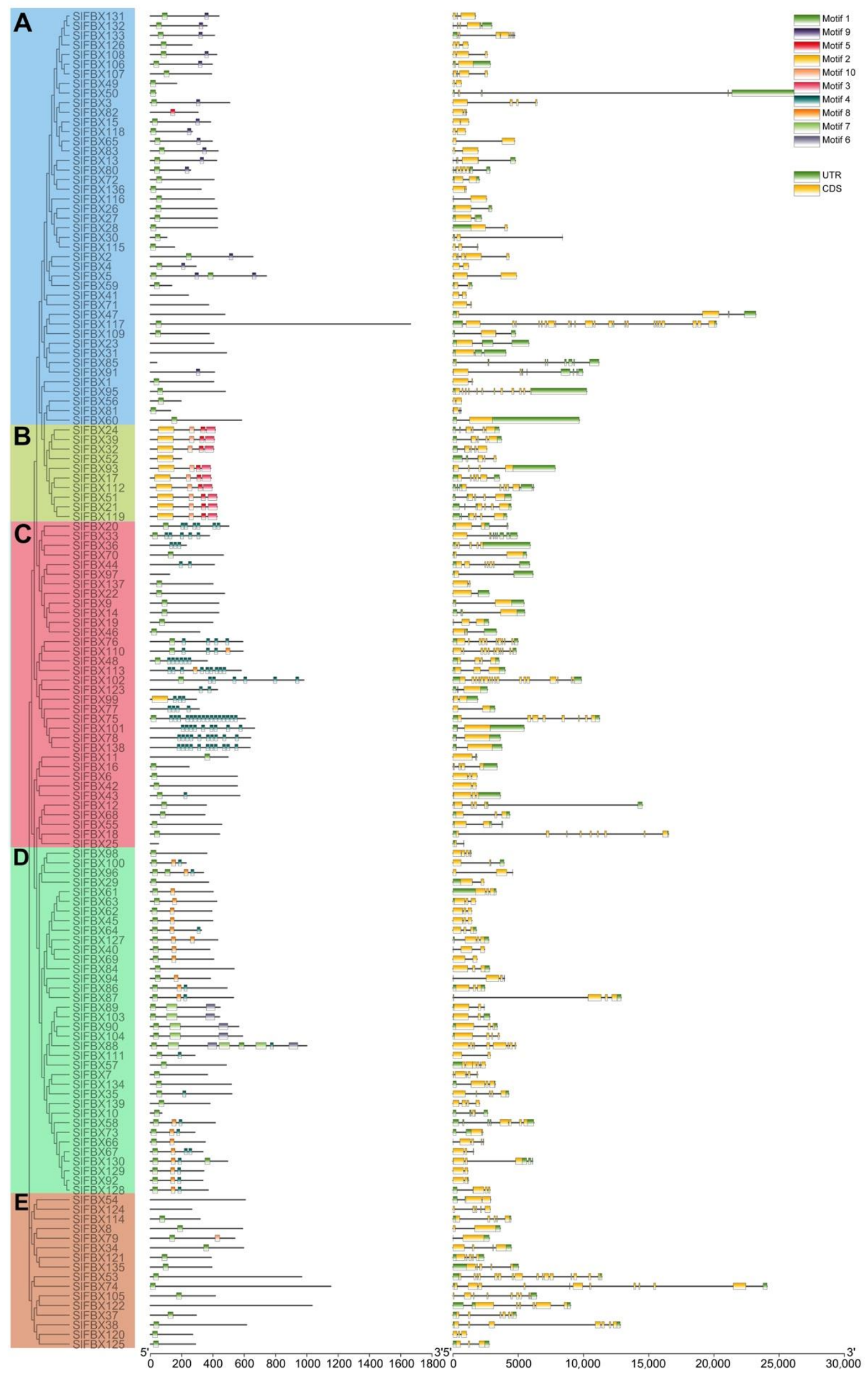

Figure 1. Phylogenetic relationships, conserved motifs of SIFBX proteins and structures of SlFBX genes in tomato. A-E represent different sub-families of SIFBX genes. 


\subsection{Phylogenetic Analysis of SlFBX Gene Family}

In order to explore the phylogenetic relationship of F-box gene family, a total of $839 \mathrm{~F}$ box genes were identified in S. lycopersicum, N. attenuata, S. tuberosum and C. canephora. And a species tree was built based on their CDS sequence, as shown in Figure 2a. There are 161 F-box genes in C. canephora, 256 F-box genes in N. attenuata and 283 F-box genes in S. tuberosum (as shown in Figure 2b). Based on the full-length of the protein sequence from 839 F-box genes, a phylogenetic tree was drawn as shown in Figure 2c. It can be seen that 139 SlFBX genes were randomly distributed in 4 groups (43 SIFBX genes in group A, 41 SIFBX genes in group B, 29 SlFBX genes in group C and 26 SlFBX genes in group D). According to Figure 2a, the 4 species have a difference in phylogenetics, but none of all $F$-box genes showed significant species differences, which to some extent reflected that the evolutionary relationship of tomato F-box genes was relatively conservative. SlFBX genes were produced before the differentiation of these species.

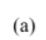

(b)

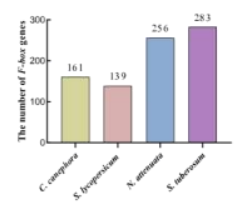

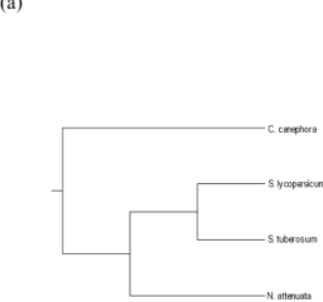

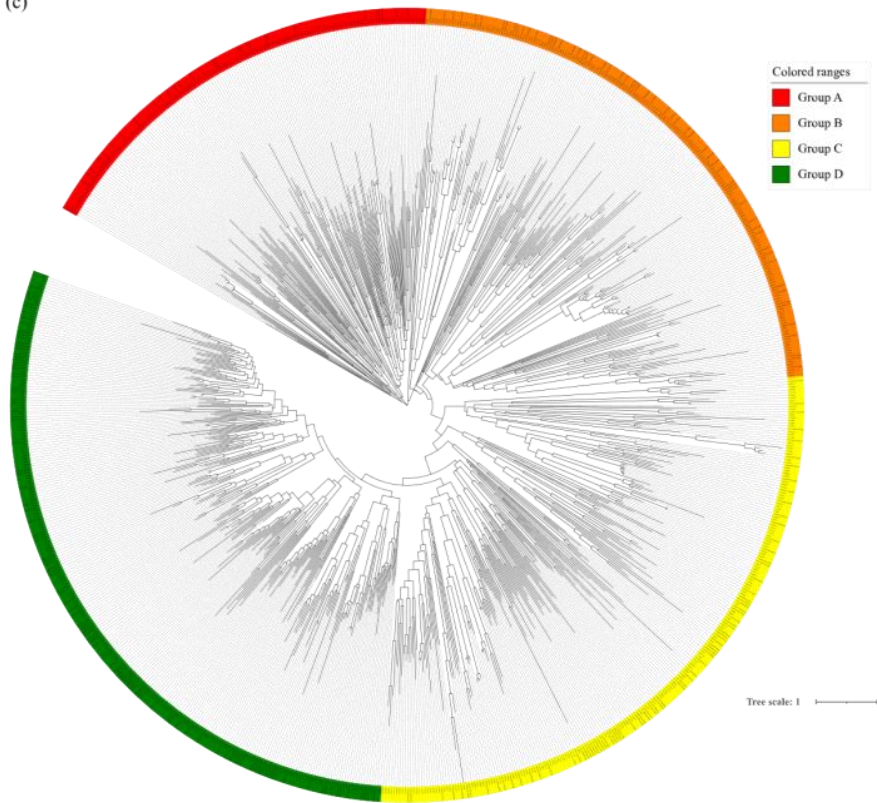

Figure 2. Phylogenetic relationship of F-box gene family. (a) Phylogenetic tree of 4 species. (b) Number distribution of F-box members in 4 species. (c) Phylogenetic relationships of F-box proteins identified in S. lycopersicum, N. attenuata, S. tuberosum and C. canephora.

\subsection{Promoter Cis-element Analysis}

The 1500 bp sequence upstream of the SIFBX genes was selected and submitted to the PlantCARE database for the analysis of promoter cis-element. Statistics of all these promoter cis-elements and their frequency in all SIFBX genes were shown in Supplementary Table S3. As shown in Figure 3, some cis-acting elements with unknown functions or less frequent occurrences (less than 20) were removed, and then TBtools were used to create a heatmap visualization. These cis-elements are associated with plant hormones and environmental responses. Such as wound-responsive element (WUN-motif), methyl jasmonate (MeJA) responsive elements (TGACG-motif), the MeJA-responsiveness (CGTCAmotif), light responsive element (GT1-motif), anaerobic induction element (ARE), stressresponse element (STRE), cis-acting element involved in the abscisic acid responsiveness (ABRE), ethylene-responsive element (ERE) and low temperature response (LTR element). In addition, there are nine cis-acting elements that appear only once in all SIFBX genes and, although these nine cis-acting elements appear very infrequently, they still have important functions such as the auxin-responsive element (AuxRE). 


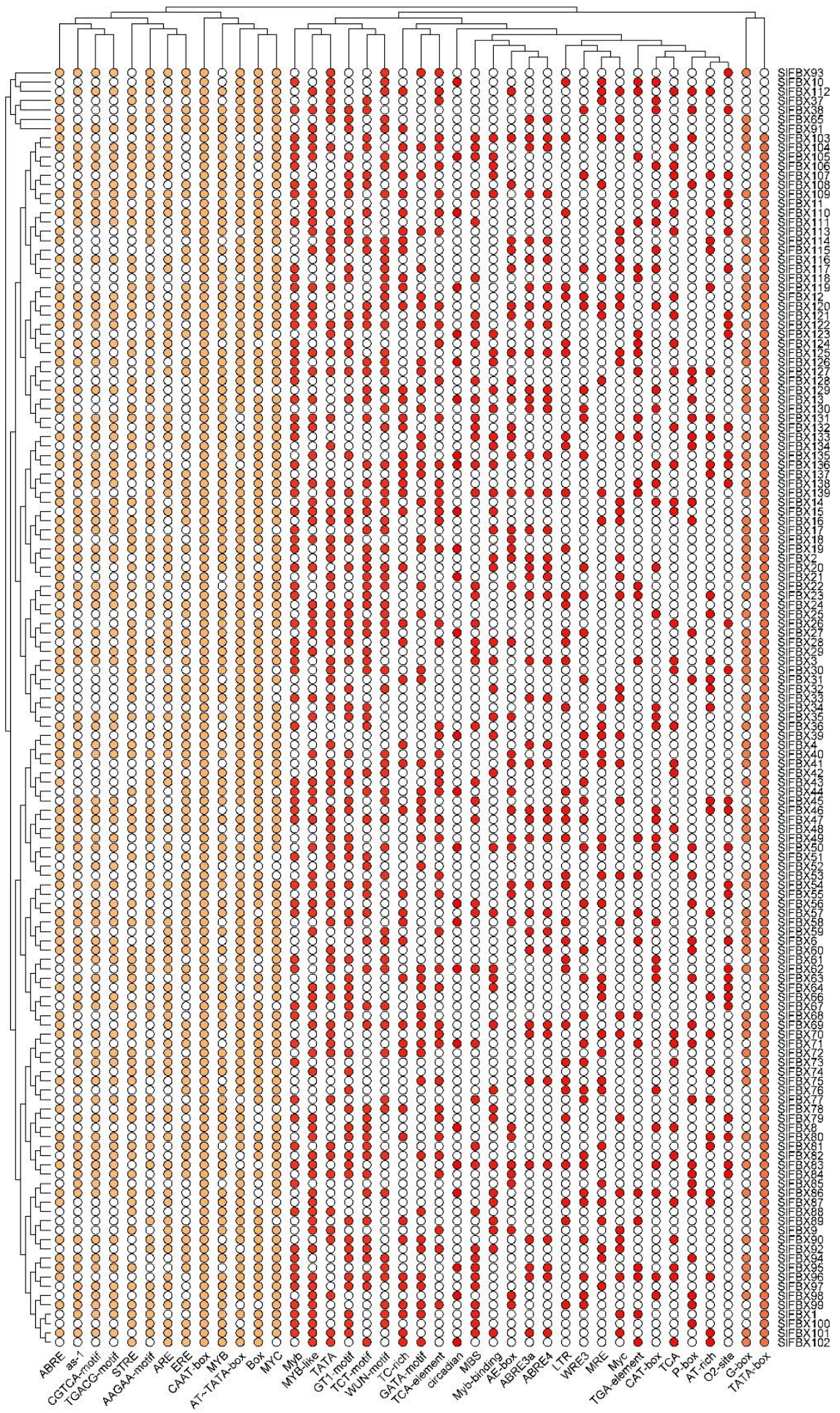

Figure 3. The cis-element of promoter in SIFBX gene family. The depth of the color represents the number of times cis-element occurs.

\subsection{Chromosome Location Analysis}

In order to explore whether the SIFBX gene family is distributed regularly, the chromosomal locations of all SlFBX genes were mapped. The location of genes on chromosomes is shown in Figure 4. Except that SlFBX1 to SlFBX7 cannot be located on any of the 12 chromosomes of tomato, the remaining 132 SIFBX genes can be located on chromosomes. Except that there are only 2 SIFBX genes on chromosome 12, there are more SIFBX genes distributed on other chromosomes. In particular, 19 SlFBX genes are distributed on chro- 
mosome 7. At the same time, most of the genes are located far away from the centromeres, which may also indicate that gene replication is more likely to occur in loosely arranged regions of chromatin.

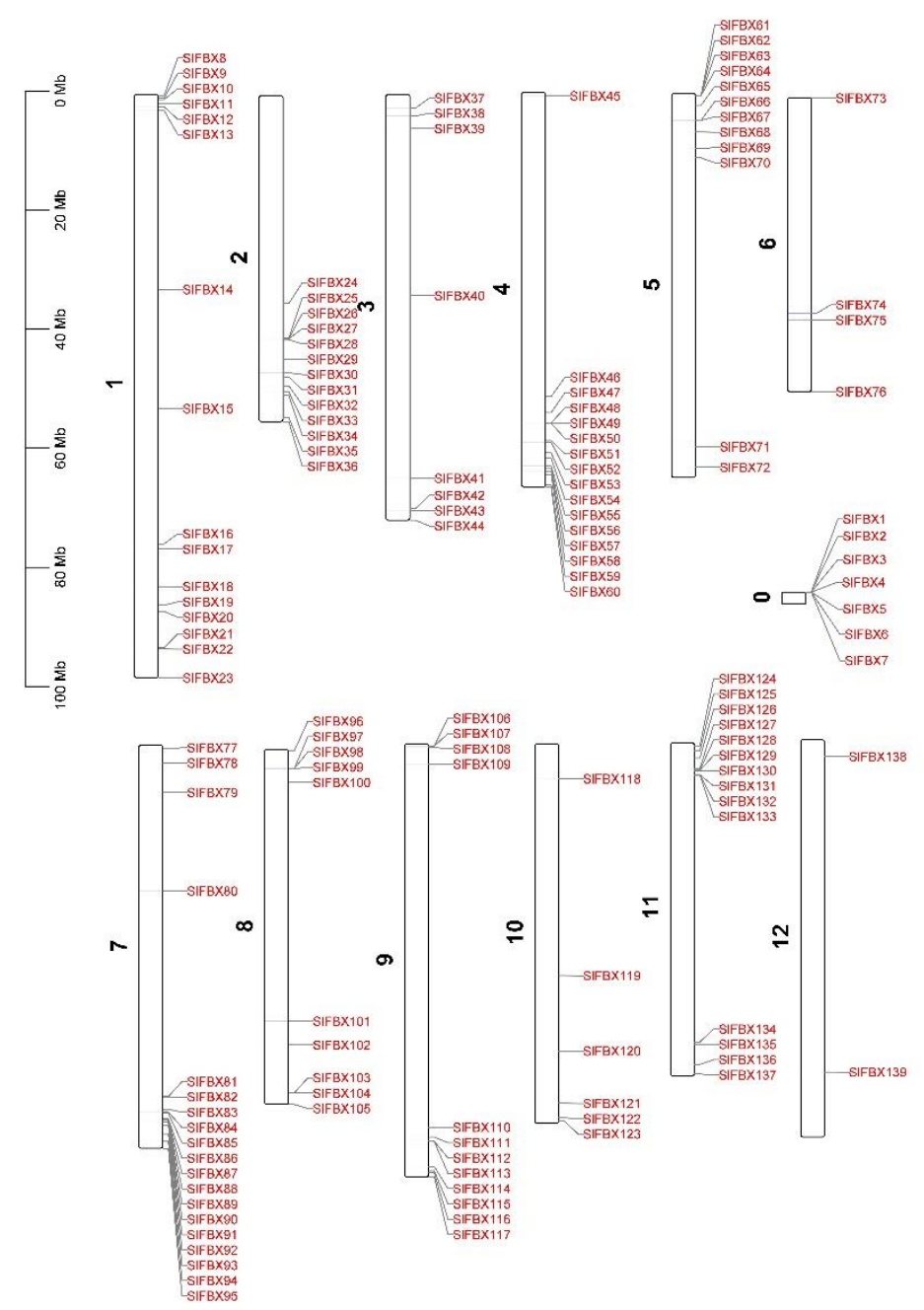

Figure 4. Chromosomal locations of SIFBX genes in tomato, 1 to 12 is the tomato's 12 chromosomes, with 0 representing the location of genes not located on the chromosome.

\subsection{Expansion and Evolutionary Analysis}

Gene duplication plays an important role in the evolution of the genome; it may accumulate evolutionary raw materials in the process of replication, thus contributing to plant evolution [42]. In particular, whole genome duplication (WGD) and tandem duplication (TD) have been found to be important for the expansion of many multigene families [43]. Therefore, this study also analyzed whether there were TD among 139 SlFBX genes, so as to explore the evolutionary relationship between SIFBX genes. There are 21 $S I F B X$ genes have a replication relationship in SIFBX gene family as shown in Table 1 . Six pairs of genes (ten genes) had TD. And 11 genes of SIFBX genes had WGD, six genes had transposed duplication (TRD) relationship, only four genes had proximal duplication (PD) relationship. The values of $\mathrm{Ka} / \mathrm{Ks}$ range from 0.1586 to 1.8618 . However, only four pairs of genes had $\mathrm{Ka} / \mathrm{Ks}$ greater than one, and the rest were all less than one, indicating that most of the replication-related SIFBX genes were purifying selection. The earliest differentiation occurred in 73.9437 million years ago. The position of these WGD genes in the genome is shown in Figure 5. 
Table 1. The duplication pairs genes of SlFBX gene family in tomato.

\begin{tabular}{cccccc}
\hline Duplicate 1 & Duplicate 2 & E-Value & Mode & Ka/Ks & Time(Mya *) \\
\hline SlFBX52 & SlFBX32 & $1 \times 10^{-99}$ & TRD & 0.7449 & 8.8202 \\
SlFBX48 & SlFBX78 & $9 \times 10^{-11}$ & TRD & 1.3014 & 34.7772 \\
SlFBX101 & SlFBX78 & 0 & TRD & 0.1443 & 73.9437 \\
SlFBX102 & SlFBX78 & $4 \times 10^{-13}$ & TRD & 1.1327 & 37.7539 \\
SlFBX23 & SlFBX31 & $2 \times 10^{-36}$ & WGD & 0.8398 & 34.3571 \\
SlFBX24 & SlFBX32 & 0 & WGD & 0.2099 & 18.9381 \\
SlFBX24 & SlFBX39 & 0 & WGD & 0.1586 & 20.7803 \\
SlFBX32 & SlFBX39 & 0 & WGD & 0.1820 & 19.4613 \\
SlFBX76 & SlFBX110 & 0 & WGD & 0.1879 & 25.0713 \\
SlFBX138 & SlFBX78 & 0 & WGD & 0.2358 & 23.4021 \\
SlFBX89 & SlFBX103 & 0 & WGD & 0.5185 & 1.3042 \\
SlFBX88 & SlFBX89 & $4 \times 10^{-106}$ & TD & 1.8618 & 5.9052 \\
SlFBX131 & SlFBX132 & 0 & TD & 0.9049 & 6.3030 \\
SIFBX132 & SlFBX133 & $1 \times 10^{-120}$ & TD & 0.9152 & 12.4690 \\
SlFBX62 & SlFBX63 & 0 & TD & 0.4898 & 13.1833 \\
SlFBX63 & SlFBX64 & $2 \times 10^{-89}$ & TD & 0.6093 & 19.6296 \\
SlFBX66 & SlFBX67 & $2 \times 10^{-111}$ & TD & 0.5459 & 19.4655 \\
SIFBX106 & SlFBX107 & $8 \times 10^{-154}$ & PD & 1.0846 & 7.2143 \\
SlFBX26 & SlFBX27 & $4 \times 10^{-118}$ & PD & 0.5952 & 20.0988 \\
\hline
\end{tabular}

${ }^{*}$ Mya means million years ago.

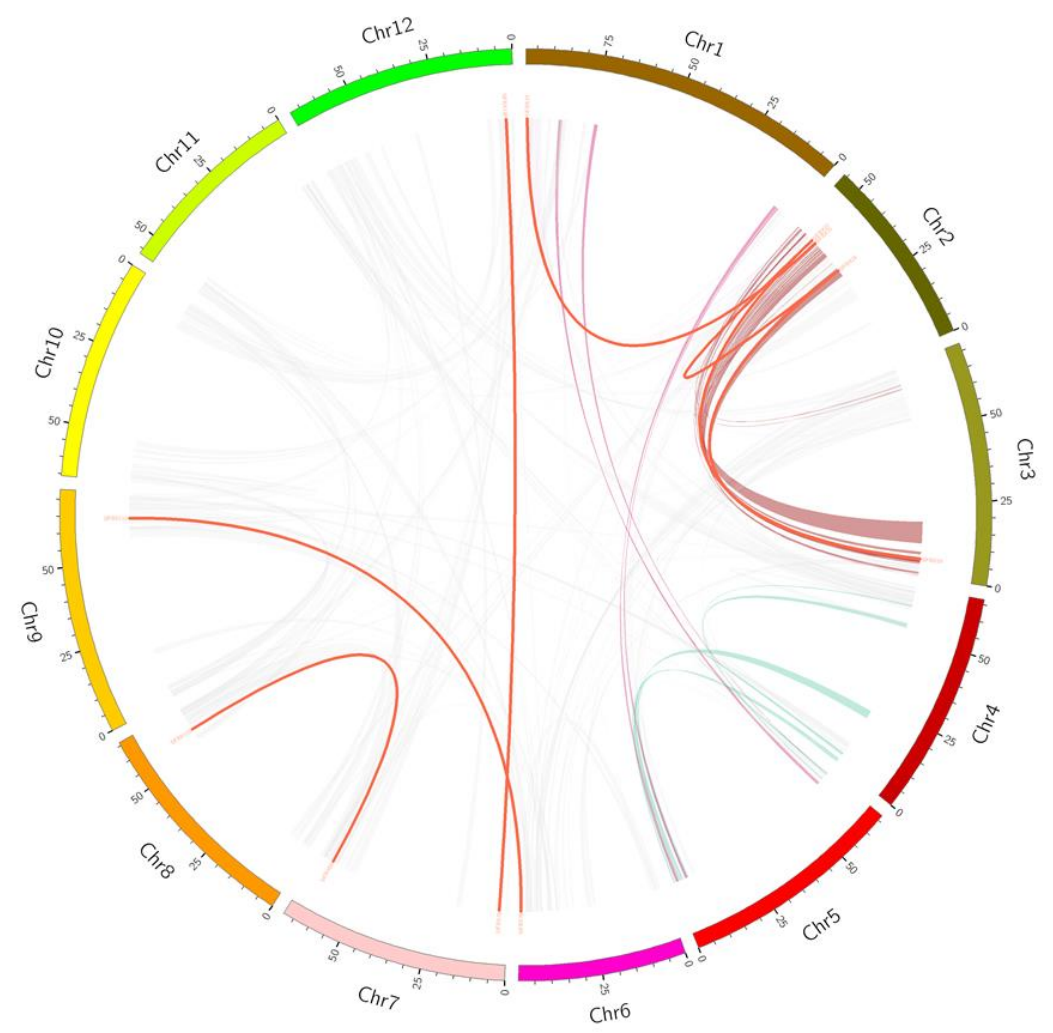

Figure 5. The syntenic pairs of tomato F-box genes from different duplication mode diagrams. The syntenic pairs from whole genome duplication (WGD) were linked by red lines. Purple, green and brown represent syntenic regions with large segments. The others syntenic pairs genes were shown with grey lines.

\subsection{Expression Analysis of SlFBX Genes Based on RNA-Seq}

Three groups of RNA-Seq data including tomato, treated with low temperature (cold), drought and without treatment (control), were used for this analysis. All of reads from the 
RNA-Seq data were mapped to the reference genome, 139 SIFBX genes were mapped under control, cold stress and drought stress. About $82.7 \%(115 / 139)$ SlFBX genes have a different expression in three groups of RNA-Seq data. All of the 139 genes were seen to have unique expression patterns under different conditions, but there are 24 SlFBX genes were not expressed in any of the three RNA-Seq data, as shown in Figure 6. Meanwhile, some genes showed an up-regulated expression trend in a single group and showed down-regulated or inactive expression in other groups. For example, the group I in control, the group II in cold and the group III in drought had a high up-regulated expression patterns only in their respective groups. The different expression patterns of all SIFBX genes also indirectly revealed the functional diversity of SIFBX gene family in tomato growth and development.

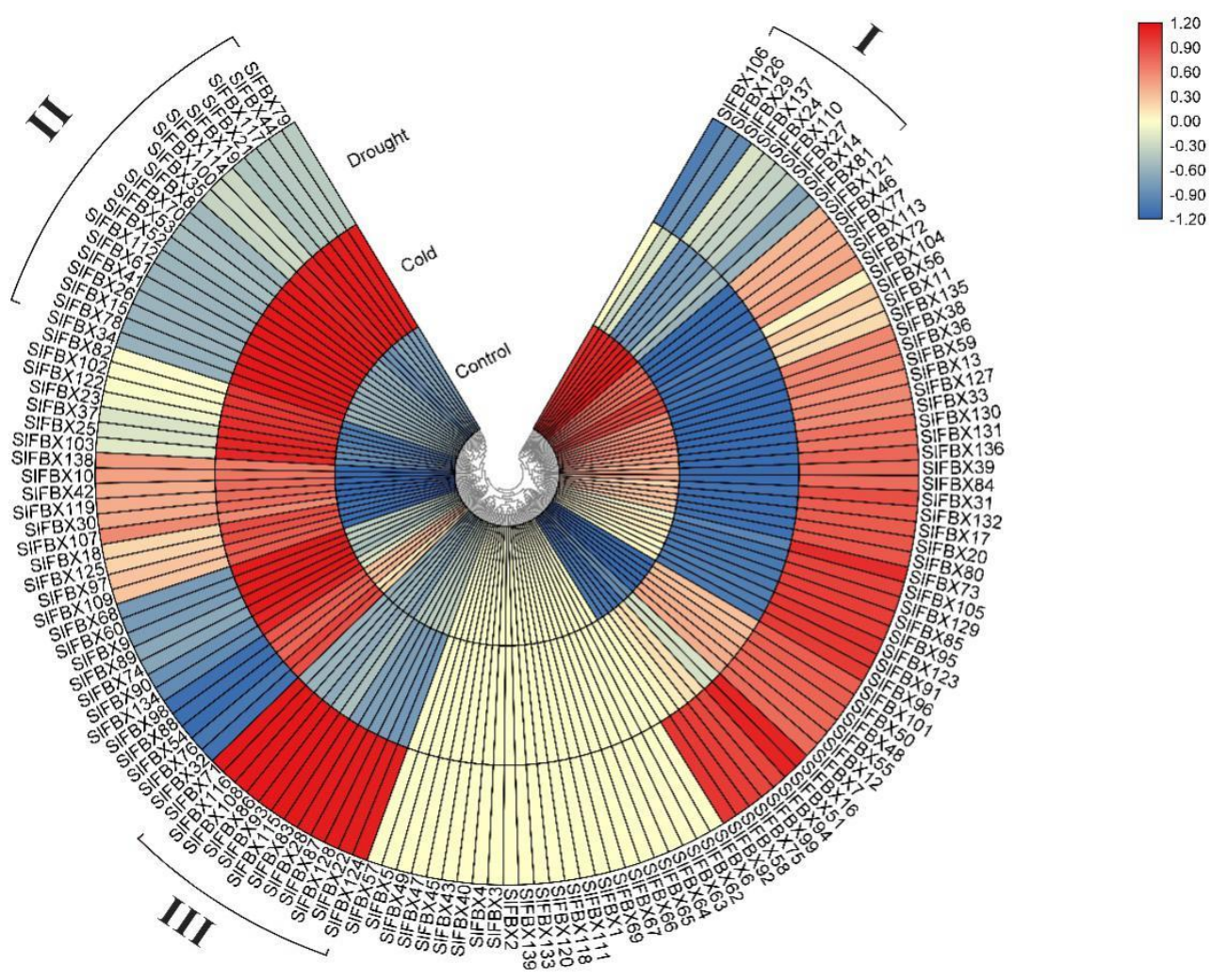

Figure 6. Transcriptional profiles of SIFBX gene family members in tomato under elevated cold stress and drought stress. blocks with colors indicate low/down expression (blue), high/up expression (red), and non-expression/no change (yellow).

\subsection{Expression Analysis of SlFBX Genes under Stress Conditions}

In order to verify the accuracy of RNA-Seq data and to investigate the response of the SIFBX gene family in tomato to abiotic stress (cold and drought) and hormones treatment, this study selected two SlFBX genes from each phylogenetic subtribe, a total of 10 genes, namely SlFBX5, SlFBX24, SlFBX33, SlFBX38, SlFBX42, SlFBX51, SlFBX65, SlFBX67, SlFBX79, SlFBX90. qRT-PCR detected the expression of the 10 members of the SIFBX gene family. The results in Figure 7 reveal that the expression of SlFBX51, SIFBX65 and SIFBX79 was significantly up-regulated under cold stress, especially, SlFBX79 expression was up-regulated about 20 times after $48 \mathrm{~h}$ of cold stress. SlFBX5, SlFBX67 and SIFBX90 also tended to be up-regulated after $48 \mathrm{~h}$ of cold stress. However, SIFBX24 and SIFBX33 showed an up-regulated trend only at $6 \mathrm{~h}$ or $12 \mathrm{~h}$ of cold treatment but showed an obvious down-regulated trend after $24 \mathrm{~h}$. 

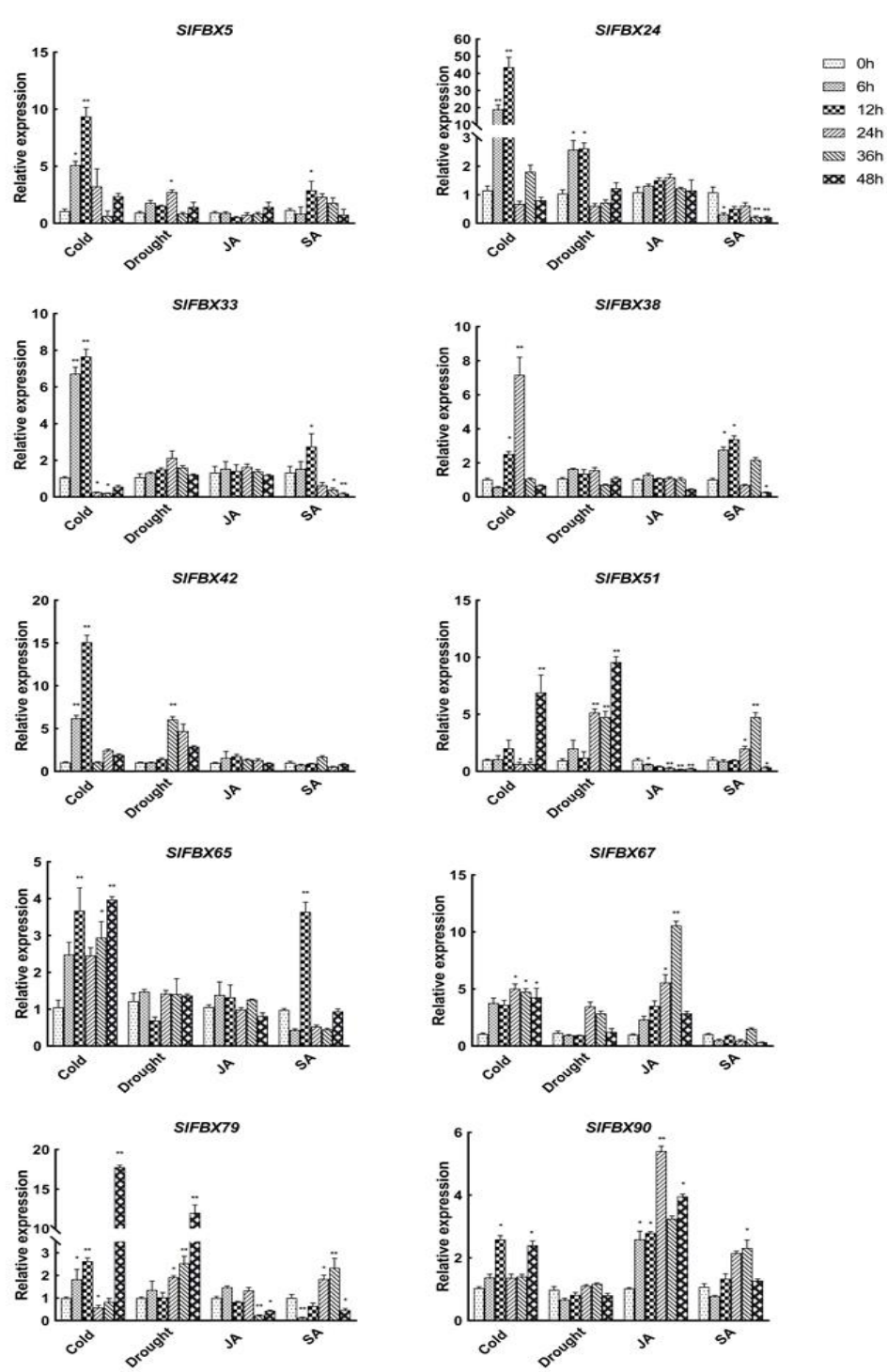

Figure 7. Relative expression analysis of 10 genes in the SIFBX gene family under cold stress, drought stress, JA treatment and SA treatment in tomato. ANOVA was used to test significance $(p<0.05$ indicates significant difference, indicated by $* ;<0.001$ indicates high significance, indicated by ${ }^{* *}$ ).

The expression of SIFBX79 and SlFBX51 also increased significantly under drought, and they have similar expression patterns under drought. The expressions of SIFBX51 and SIFBX79 were up-regulated 10 times and 12 times respectively under drought stress at $48 \mathrm{~h}$. In the first $24 \mathrm{~h}$ of drought stress, SIFBX5, SlFBX24 and SIFBX42 showed a trend of up-regulated expression, but their expression decreased gradually with the passage of time. The remained genes showed no obvious up-regulated or down-regulated under drought.

For the expression of 10 genes under JA treatment, SIFBX51, SIFBX65 and SlFBX79 showed a relatively obvious down-regulated trend. SIFBX67 and SIFBX90 showed a trend of up-regulated expression within $48 \mathrm{~h}$, but SIFBX67 showed a significant up-regulated expression at $36 \mathrm{~h}$, and the expression at $48 \mathrm{~h}$ was less than that at $36 \mathrm{~h}$, but still higher than $0 \mathrm{~h}$. The expression level of SlFBX90 after JA treatment were more than twice that of the control group $(0 \mathrm{~h})$. For SA treatment, all of the genes except SlFBX90 showed a downregulated expression trend after $48 \mathrm{~h}$, SIFBX90 was also only a slightly up-regulated expression.

\section{Discussion}

Abiotic stress seriously affects the growth and development of plants. In the long process of evolution, plants have produced many physiological and biochemical mech- 
anisms to resist these stresses. Tomato is one of the most important vegetable crops in the world [44]. However, its resistance to abiotic stress is relatively weak [45]. When tomatoes are grown in cold or drought conditions, the growth and development of tomato will be seriously affected, and even lead to death [46]. As one of the super families in plants, F-box family plays a very important role in many aspects of plant growth and development [47]. In previous studies, many F-box gene families have been identified in plants, such as Oryza sativa [19], Malus [48], Pyrus bretschneideri [49], Hordeum vulgare [50], and Zea mays [51]. Plant's F-box protein has many members and complex functions. At present, the function of F-box has mainly in the aspects of hormone response and photomorphogenesis. In the ethylene signaling pathway, F-box protein negatively regulates the ethylene pathway [52]. F-box protein is also a positive regulator of gibberellic and auxin signaling pathways [52-54]. However, there have been few studies on the F-box gene family of the tomato.

In this study, 139 members of the SIFBX gene family in tomato were identified, the sequence characteristics and structures of SIFBX genes, conserved motif, phylogenetic relationships, cis-elements of promoter regions, tandem duplication and whole genome duplication were obtained. In addition, expression patterns of 10 SlFBX genes were explored based on the data of transcriptome and validated the result by qRT-PCR.

As shown in Supplementary Table S2, the average molecular weight of members of the SIFBX gene family is $48.6 \mathrm{KDa}$, the average $\mathrm{pI}$ is 7.66 , close to neutral $\mathrm{pH}$.

In plants, different F-box proteins bind to SCF subunits to recognize different substrates. The domain at the C-terminal of the F-box protein is the determinant of binding to different SCF subunits. F-box protein plays a role in a variety of signal transduction pathways, such as stress resistance, photomorphogenesis, and hormone response [55,56]. Kelch repeats, LRR domains, WD40 domains and FBA domains were identified in the SIFBX gene family in tomato. These domains have important functions in many aspects of plant growth and development. SIFBX14, SIFBX14, SIFBX22, SIFBX46, S1FBX60, S1FBX79, SIFBX98 and SIFBX137 contain the Kelch structure, and the number of Kelch varies from 4 (SIFBX137) to 16 (SIFBX79), Kelch repeats domain participates in the circadian clock regulation process and recognize substrates and mediates their ubiquitination. [57,58]. SlFBX36, SIFBX48, SIFBX75, SIFBX94, SIFBX99, SIFBX101 contain the LRR domain. The disease resistance of LRR has been extensively studied in plants, such as S. lycopersicum [59], Oryza sativa [60] and Arabidopsis [61]. LRR recognizes flagellin (flg22) in the defense responses in Arabidopsis [62], and priming the plant resistance [63]. Seven WD40 domain has identified in SIFBX18, WD40 domain not only promote protein interaction [64], but also participate in the flavonoid biosynthesis in Arabidopsis [65], Perilla frutescens [66], Zea mays [67], Oryza sativa [68], Medicago truncatula [69] and Vitis vinifera [70]. There are about $29.3 \%(27 / 139)$ of SIFBX proteins containing the FBA domain, the FBA domain is involved in carbohydrate metabolism [71] and in signal transductions [72] in Zea mays [73], Arabidopsis [65], Spinacia oleracea [74], Nicotiana tabacum [75], Sesuvium portulacastrum [76] and S. lycopersicum [77]. Although these domains are not all of the structural domains of SIFBX genes, it can be seen that SIFBX genes play an important role in many aspects of plant growth and development.

In all 139 SIFBX genes, 137 genes were identified SIFBX cis upstream of the promoter function components were shown in Figure 3. There are 0 cis-element in SlFBX5 and SlFBX7, inaccuracy in genome assembly and annotation may be the reason why cis-elements were not obtained in SIFBX5 and SIFBX7. So, improving the optimization of existing genome for scientific research and production practice is of significance. There are three category functions of cis-element: growth and development (such as G-box) [78], hormonal response (such as ABRE) [79] and stress response (such as LTR) [80]. All cis-elements of SlFBX genes are shown in Supplementary Table S3.

New genes were produced with the gene duplication if a mutation occurred, and WGD/WGT events could explain why the F-Box family has so many members and functions in a variety of plants. Members of the SIFBX gene family have various functions. Then, 139 SIFBX genes were divided into five subtribes according to the full-length sequence of 
proteins as shown in Figure 1. SIFBX genes in the same subtribes are highly conserved in protein sequence, so we can find that the genes have the TD relationship are all divided into the same subtribes, such as the subtribe A, which contains tandem duplication genes SlFBX131, SlFBX132 and SIFBX133. Meanwhile, according to Table 1, there are PD and TRD relationships in the SIFBX gene family, which gives new impetus to the increase of the number of SIFBX genes and their differentiation.

The phylogenetic relationships of 839 F-box proteins were shown in Figure 2, S. lycopersicum, N. attenuata and S. tuberosum are members of Solanaceae, and C. canephora is close to the Solanaceae family. Although not all four plants belong to the Solanaceae, they do not show a relatively long evolutionary distance in terms of F-box genes' evolution. For example, in group A, the S. lycopersicum's gene SIFBX123, the N. attenuata's gene OIT01487, the C. canephora's gene CDP15407 and the S. tuberosum's gene PGSC0003DMT40006975 are all on the same branch, and they are very close in evolutionary distance. Meanwhile, WGD (or whole genome triplications, WGT) plays an important role in the evolution of F-box genes. Combining Figures 2 and 4, group A, group B and group $C$ have the WGD genes in Figure 2c, such as SIFBX89 and SIFBX 103 in group A, SIFBX138 and SlFBX78 in group $B$, SIFBX76 and SIFBX110 in group C, there are none of the WGD or WGT genes in group D. But there are only two pairs of PD genes that were all in group D, which may indicate that PD genes of the other three species are mainly concentrated in group D, based on structural similarity. In addition, the number of F-box gene in S. lycopersicum was much smaller than that in $S$. tuberosum and N. attenuata, which may indicate that only a small amount of F-box gene was copied in WGD or WGT events in S. lycopersicum, which leads to this result. In a word, the results not only indicate that the evolutionary relationship of F-box genes in the four species is very close, but also prove that the F-box family, as one of the largest superfamilies in plants, is very widely distributed in the four plants. WGD or WGT play an important role in the expansion of F-box gene family. Meanwhile, based on the phylogenetic relationship shown in the results, we speculate that the function of $F-b o x$ genes in other species is similar to SIFBX. In other words, these F-box genes maybe have similar functions in abiotic stress, hormonal response, or photomorphogenesis.

This study revealed that SIFBX genes could respond to four different treatments - cold stress, drought stress, JA treatment and SA treatment. This indicates that SlFBX can response to four kinds of treatments, but SIFBX expression levels are also different. In Figure 6, the expression of SIFBX genes was similar between the control group and the drought group, but different from the cold group. For example, SIFBX121 showed an up-regulated expression trend in both the control group and the drought group but showed a down-regulated expression in the cold stress group. Ten SIFBX genes were selected for qRT-PCR, and the results of qRT-PCR showed that the expression of most of the genes was consistent with the results obtained from transcriptomic data analysis. However, there is a subtle difference. For example, the expression of SIFBX5 can be detected in qRT-PCR, but it is not shown in transcriptomic data. Although SIFBX5 does not show significant difference in expression under different stress, the possible reason is that there are some errors in transcriptomic data measurement. This study found that SIFBX51 had a significantly up-regulated expression under both cold stress and drought stress, and a significantly up-regulated expression under SA treatment at $36 \mathrm{~h}$, but showed a significantly downregulated expression at $48 \mathrm{~h}$. Moreover, the expression change of SIFBX24 was the most significantly induced by cold stress. At 12 h, SlFBX24 was up-regulated nearly 50 times, but the expression after $24 \mathrm{~h}$ was not significant compared with that at $0 \mathrm{~h}$, which may indicate that SIFBX24 responded quickly in the early stage of cold stress and played an important role. In addition, this study showed a different tendency compared with the RNA-seq data from Zhou's (2019) study [25]. In transcriptional analysis, SlFBX79 showed upregulation only in the cold stress group, but the qRT-PCR results showed that SIFBX79 also showed an up-regulated trend under drought, although the upregulation multiple was smaller than that under cold. 


\section{Conclusions}

In this study, a total of 139 SIFBX genes were identified by using bioinformatic methods in tomato. Gene structure, chromosomal location, phylogenetic relationship, duplication events, and expression based on transcriptome data were analyzed in detail. In addition, ten genes were selected and qRT-PCR was used in order to verify the accuracy of transcriptome data and to explore the true expression of SIFBX under abiotic stress. The 139 SIFBX genes were divided into five subtribes according to their protein sequences, which have various structures and functions. In the phylogenetic analysis of the four species, all the F-box genes showed close evolutionary relationships. There were 30 genes with replication relationships, indicating that gene replication plays an important role in the generation and functional differentiation of gene families. This is the first study to confirm that SlFBX79 plays an important role in drought and cold, providing a basis for further study on the role of SIFBX gene family in tomato breeding and resistance improvement.

Supplementary Materials: The following are available online at https:/ www.mdpi.com/2073-442 5/12/3/417/s1, Figure S1: The motif of SIFBX protein sequences; Table S1: Primers for qRT-PCR; Table S2: Base information of SIFBX gene family; Table S3: Cis-elements information.

Author Contributions: A.W. and X.C. designed the research strategy, and conceived and supervised the project; F.M., N.Z., and Y.Q. wrote the manuscript; F.M., L.M., M.C., L.Y., R.L., Y.L., Y.Z., and J.L. performed the experiments and analyzed the data. Both F.M. and L.Y. drew the figures. All authors have read and agreed to the published version of the manuscript.

Funding: This research was supported by the National Natural Science Foundation of China (31872120, 32072588); National Key R\&D Program of China (2017YFE0105000); National Natural Science Foundation of Heilongjiang Province (LH2020C011); Postdoctoral Scientific Research Developmental Fund of Heilongjiang Province (LBH-Q18023).

Institutional Review Board Statement: Not applicable.

Informed Consent Statement: Not applicable.

Data Availability Statement: Data is contained within the article or supplementary materials.

Acknowledgments: This work was financially supported by the National Natural Science Foundation of China (31872120, 32072588); National Key R\&D Program of China (2017YFE0105000); National Natural Science Foundation of Heilongjiang Province (LH2020C011); Postdoctoral Scientific Research Developmental Fund of Heilongjiang Province (LBH-Q18023).

Conflicts of Interest: The authors declare no conflict of interest.

\section{References}

1. Hua, Z.; Zou, C.; Shiu, S.H.; Vierstra, R.D. Phylogenetic Comparison of F-Box (FBX) Gene Superfamily within the Plant Kingdom Reveals Divergent Evolutionary Histories Indicative of Genomic Drift. PLoS ONE 2011, 6, e16219. [CrossRef]

2. Xu, G.; Ma, H.; Nei, M.; Kong, H. Evolution of F-box genes in plants: Different modes of sequence divergence and their relationships with functional diversification. Proc. Natl. Acad. Sci. USA 2009, 106, 835-840. [CrossRef]

3. Lechner, E.; Achard, P.; Vansiri, A.; Potuschak, T.; Genschik, P. F-box proteins everywhere. Curr. Opin. Plant Biol. 2006, 9, 631-638. [CrossRef]

4. Shen, H.; Zhu, L.; Bu, Q.Y.; Huq, E. MAX2 Affects Multiple Hormones to Promote Photomorphogenesis. Mol. Plant 2012, 5, 750-762. [CrossRef]

5. $\quad$ Liu, Y.; Ji, X.; Nie, X.; Qu, M.; Zheng, L.; Tan, Z.; Zhao, H.; Huo, L.; Liu, S.; Zhang, B.; et al. Arabidopsis AtbHLH112 regulates the expression of genes involved in abiotic stress tolerance by binding to their E-box and GCG-box motifs. New Phytol. 2015, 207, 692-709. [CrossRef]

6. Gagne, J.M.; Smalle, J.; Gingerich, D.J.; Walker, J.M.; Yoo, S.D.; Yanagisawa, S.; Vierstra, R.D. Arabidopsis EIN3-binding F-box 1 and 2 form ubiquitin-protein ligases that repress ethylene action and promote growth by directing EIN3 degradation. Proc. Natl. Acad. Sci. USA 2004, 101, 6803-6808. [CrossRef] [PubMed]

7. Seki, M.; Ishida, J.; Narusaka, M.; Fujita, M.; Nanjo, T.; Umezawa, T.; Kamiya, A.; Nakajima, M.; Enju, A.; Sakurai, T.; et al. Monitoring the expression pattern of around 7,000 Arabidopsis genes under ABA treatments using a full-length cDNA microarray. Funct. Integr. Genomics 2002, 2, 282-291. [CrossRef] [PubMed]

8. Sadanandom, A.; Bailey, M.; Ewan, R.; Lee, J.; Nelis, S. The ubiquitin-proteasome system: Central modifier of plant signalling. New Phytol. 2012, 196, 13-28. [CrossRef] [PubMed] 
9. Smalle, J.; Vierstra, R.D. The Ubiquitin 26s Proteasome Proteolytic Pathway. Annu. Rev. Plant Biol. 2004, 55, 555-590. [CrossRef]

10. Gorelik, M.; Manczyk, N.; Pavlenco, A.; Kurinov, I.; Sidhu, S.S.; Sicheri, F. A Structure-Based Strategy for Engineering Selective Ubiquitin Variant Inhibitors of Skp1-Cul1-F-Box Ubiquitin Ligases. Structures 2018, 26, 1226-1236. [CrossRef]

11. Kepinski, S.; Leyser, O. The F-box protein TIR1 is an auxin receptor. Nature 2005, 435, 441-445. [CrossRef] [PubMed]

12. Bai, C.; Sen, P.; Hofmann, K.; Ma, L.; Goebl, M.; Harper, J.; Elledge, S.J. SKP1 Connects Cell Cycle Regulators to the Ubiquitin Proteolysis Machinery through a Novel Motif, the F-Box. Cell 1996, 86, 263-274. [CrossRef]

13. Kipreos, E.T.; Pagano, M. The F-box protein family. Genome Biol. 2000, 1, 3002. [CrossRef] [PubMed]

14. Somers, D.E.; Fujiwara, S. Thinking outside the F-box: Novel ligands for novel receptors. Trends Plant Sci. 2009, 14, 206-213. [CrossRef]

15. Bashir, T.; Dorrello, N.V.; Amador, V.; Guardavaccaro, D.; Pagano, M. Control of the SCF(Skp2-Cks1) ubiquitin ligase by the APC/C(Cdh1) ubiquitin ligase. Nature 2004, 428, 190-193. [CrossRef] [PubMed]

16. Beatrix, B.; Sakai, H.; Wiedmann, M. The alpha and beta subunit of the nascent polypeptide-associated complex have distinct functions. J. Biol. Chem. 2000, 275, 37838-37845. [CrossRef]

17. Burch, J.T.; Haas, A.L. Site-directed mutagenesis of ubiquitin. Differential roles for arginine in the interac-tion with ubiquitinactivating enzyme. Biochemistry 1994, 33, 7300-7308. [CrossRef]

18. Gupta, S.; Garg, V.; Kant, C.; Bhatia, S. Genome-wide survey and expression analysis of F-box genes in chickpea. BMC Genom. 2015, 16, 67. [CrossRef]

19. Jain, M.; Nijhawan, A.; Arora, R.; Pinky, A.; Ray, S.; Sharma, P.; Kapoor, S.; Tyagi, A.K.; Khurana, J.P. F-box proteins in rice. Genome-wide analysis, classification, temporal and spatial gene expres-sion during panicle and seed development, and regulation by light and abiotic stress. Plant Physiol. 2007, 143, 1467-1483. [CrossRef]

20. Chen, R.; Guo, W.; Yin, Y.; Gong, Z.H. A novel F-box protein CaF-box is involved in responses to plant hormones and abiotic stress in pepper (Capsicum annuum L.). Int. J. Mol. Sci. 2014, 15, 2413-2430. [CrossRef]

21. Zhou, S.; Sun, X.; Yin, S.; Kong, X.; Zhou, S.; Xu, Y.; Luo, Y.; Wang, W. The role of the F-box gene TaFBA1 from wheat (Triticum aestivum L.) in drought tolerance. Plant Physiol. Biochem. 2014, 84, 213-223. [CrossRef] [PubMed]

22. Calderón, M.M.T.; García, S.E.; Sosa, R.M. Characterization of novel F-box proteins in plants induced by biotic and abiotic stress. Plant Sci. 2012, 185-186, 208-217. [CrossRef] [PubMed]

23. Chinnusamy, V.; Zhu, J.; Zhu, J.K. Cold stress regulation of gene expression in plants. Trends Plant Sci. 2007, 12, 444-451. [CrossRef]

24. Yan, Y.S.; Chen, X.Y.; Yang, K.; Sun, Z.X.; Fu, Y.P.; Zhang, Y.M.; Fang, R.X. Overexpression of an F-box Protein Gene Reduces Abiotic Stress Tolerance and Promotes Root Growth in Rice. Mol. Plant 2011, 4, 190-197. [CrossRef] [PubMed]

25. Deng, H.; Pirrello, J.; Chen, Y.; Li, N.; Zhu, S.; Chirinos, X.; Bouzayen, M.; Liu, Y.; Liu, M. A novel tomato F-box protein, SlEBF3, is involved in tuning ethylene signaling during plant development and climacteric fruit ripening. Plant J. 2018, 95, 648-658. [CrossRef]

26. Li, X.; Sun, Y.; Liu, N.; Wang, P.; Pei, Y.; Liu, D.; Ma, X.; Ge, X.; Li, F.; Huo, Y. Enhanced resistance to Verticillium dahliae mediated by an F-box protein GhACIF1 from Gossy-pium hirsutum. Plant Sci. 2019, 284, 127-134. [CrossRef]

27. Zhou, R.; Yu, X.; Zhao, T.; Ottosen, C.O.; Rosenqvist, E.; Wu, Z. Physiological analysis and transcriptome sequencing reveal the effects of combined cold and drought on tomato leaf. BMC Plant Biol. 2019, 19, 1-14. [CrossRef] [PubMed]

28. Finn, R.D.; Clements, J.; Eddy, S.R. HMMER web server: Interactive sequence similarity searching. Nucleic Acids Res. 2011, 39, W29-W37. [CrossRef]

29. Bailey, T.L.; Boden, M.; Buske, F.A.; Frith, M.; Grant, C.E.; Clementi, L.; Ren, J.; Li, W.W.; Noble, W.S. MEME SUITE: Tools for motif discovery and searching. Nucleic Acids Res. 2009, 37, w202-w208. [CrossRef]

30. Kumar, S.; Stecher, G.; Tamura, K. MEGA7: Molecular Evolutionary Genetics Analysis Version 7.0 for Bigger Datasets. Mol. Biol. Evol. 2016, 33, 1870-1874. [CrossRef]

31. Chen, C.; Chen, H.; Zhang, Y.; Thomas, H.R.; Frank, M.H.; He, Y.; Xia, R. TBtools: An Integrative Toolkit Developed for Interactive Analyses of Big Biological Data. Mol. Plant 2020, 13, 1194-1202. [CrossRef] [PubMed]

32. Hurst, L.D. The Ka/Ks ratio: Diagnosing the form of sequence evolution. Trends Genet. 2002, 18, 486. [CrossRef]

33. Altschul, S.F. Basic local alignment search tool (BLAST). J. Mol. Biol. 2012, 215, 403-410. [CrossRef]

34. Vatansever, R.; Koc, I.; Ozyigit, I.I.; Sen, U.; Uras, M.E.; Anjum, N.A.; Pereira, E.; Filiz, E. Genome-wide identification and expression analysis of sulfate transporter (SULTR) genes in potato (Solanum tuberosum L.). Planta 2016, 244, 1167-1183. [CrossRef]

35. Wang, D.; Zhang, Y.; Zhang, Z.; Zhu, J.; Yu, J. KaKs_Calculator 2.0: A Toolkit Incorporating Gamma-Series Methods and Sliding Window Strategies. Genom. Proteom. Bioinform. 2010, 8, 77-80. [CrossRef]

36. Koch, A.M.; Haubold, B.; Olds, M.T. Comparative evolutionary analysis of chalcone synthase and alcohol dehydrogenase loci in Arabidopsis, Arabis, and related genera (Brassicaceae). Mol. Biol. Evol. 2000, 17, 1483-1498. [CrossRef]

37. Wang, Y.; Li, J.; Paterson, A.H. MCScanX-transposed: Detecting transposed gene duplications based on multiple colinearity scans. Bioinformatics 2013, 29, 1458-1460. [CrossRef]

38. Krzywinski, M.; Schein, J.; Birol, I.; Connors, J.; Gascoyne, R.; Horsman, D.; Jones, S.J.; Marra, M.A. Circos: An information aesthetic for comparative genomics. Genome Res. 2009, 19, 1639-1645. [CrossRef]

39. Kim, D.; Langmead, B.; Salzberg, S. HISAT: Hierarchical Indexing for Spliced Alignment of Transcripts. BioRxiv 2014. [CrossRef] 
40. Yang, L.; Smyth, G.K.; Wei, S. Feature Counts: An efficient general purpose program for assigning sequence reads to genomic features. Bioinformatics 2014, 30, 923-930.

41. Livak, J.K.; Schmittgen, T.D. Analysis of Relative Gene Expression Data using Real-Time Quantitative PCR. Method 2002, 25, 402-408. [CrossRef] [PubMed]

42. Sampedro, J.; Lee, Y.; Carey, R.E.; Depamphilis, C.; Cosgrove, D.J. Use of genomic history to improve phylogeny and understanding of births and deaths in a gene family. Plant J. 2005, 44, 409-419. [CrossRef] [PubMed]

43. Kong, H.; Landherr, L.L.; Frohlich, M.W.; Mack, L.J.; MA, H.; De Pamphilis, C.W. Patterns of gene duplication in the plant SKP1 gene family in angiosperms: Evidence for multiple mechanisms of rapid gene birth. Plant J. 2010, 50, 873-885. [CrossRef] [PubMed]

44. Guo, T.; Zhang, X.; Li, Y.; Liu, C.; Wang, N.; Jiang, Q.; Wu, J.; Ma, F.; Liu, C. Overexpression of MdARD4 Accelerates Fruit Ripening and Increases Cold Hardiness in Tomato. Int. J. Mol. Sci. 2020, 21, 6182. [CrossRef]

45. Alenazi, M.M.; Shafiq, M.; Alsadon, A.A.; Alhelal, I.M.; Alhamdan, A.M.; Solieman, T.H.; Ibrahim, A.A.; Shady, M.R.; Al-Selwey, W.A. Improved functional and nutritional properties of tomato fruit during cold storage. Saudi J. Biol. Sci. 2020, 27, 1467-1474 [CrossRef] [PubMed]

46. Mahajan, S.; Tuteja, N. Cold, salinity and drought stresses: An overview. Arch. Biochem. Biophys. 2005, 444, 139-158. [CrossRef]

47. Majee, M.; Kumar, S.; Kathare, P.K.; Wu, S.; Gingerich, D.; Nihar, N.R.; Salaita, L.; Dinkins, R.; Martin, K.; Goodin, M.; et al. Kelch F-Box Protein Positively Influences Arabidopsis Seed Germination By Targeting Phy-Tochrome-Interacting Factor. Proc. Natl. Acad. Sci. USA 2018, 115, E4120-E4129. [CrossRef]

48. Cui, H.R.; Zhang, Z.R.; Lv, W.; Xu, J.N.; Wang, X.Y. Genome-wide characterization and analysis of F-box protein-encoding genes in the Malus domestica genome. Mol. Genet. Genom. 2015, 290, 1435-1446. [CrossRef]

49. Wang, G.M.; Yin, H.; Qiao, X.; Tan, X.; Gu, C.; Wang, B.H.; Cheng, R.; Wang, Y.Z.; Zhang, S.L. F-box genes: Genome-wide expansion, evolution and their contribution to pollen growth in pear (Pyrus bretschneideri). Plant Sci. 2016, 253, 164-175. [CrossRef]

50. Zhang, L.; Wang, S.; Chen, Y.; Dong, M.; Fang, Y.; Zhang, X.; Tong, T.; Zhang, Z.; Zheng, J.; Xue, D.; et al. Genome-Wide Identification of the F-box Gene Family and Expression Analysis under Drought and Salt Stress in Barley. Phyton 2020, 89, $229-251$. [CrossRef]

51. Jia, F.; Wu, B.; Li, H.; Huang, J.; Zheng, C. Genome-wide identification and characterisation of F-box family in maize. Mol. Genet. Genom. 2013, 288, 559-577. [CrossRef]

52. Guo, H.; Ecker, J.R. Plant responses to ethylene gas are mediated by SCF(EBF1/EBF2)-dependent proteolysis of EIN3 transcription factor. Cell 2003, 115, 667-677. [CrossRef]

53. Sasaki, A.; Itoh, H.; Gomi, K.; Tanaka, U.M.; Ishiyama, K.; Kobayashi, M.; Jeong, D.H.; An, G.; Kitano, H.; Ashikari, M.; et al. Accumulation of Phosphorylated Repressor for Gibberellin Signaling in an F-box Mutant. Science 2003, 299, 1896-1898. [CrossRef]

54. Kepinski, S.; Leyser, O. The Arabidopsis F-box protein TIR1 is an auxin receptor. Nat. Cell Biol. 2005, 435, 446-451. [CrossRef]

55. Moon, J.; Parry, G.; Estelle, M. The Ubiquitin-Proteasome Pathway and Plant Development. Plant Cell 2004, 16, 3181-3195. [CrossRef] [PubMed]

56. Zhang, Y.; Xu, W.; Li, Z.; Deng, X.W.; Wu, W.; Xue, Y. F-box protein DOR functions as a novel inhibitory factor for abscisic acid-induced stomatal closure under drought stress in Arabidopsis. Plant Physiol. 2008, 148, 2121-2133. [CrossRef] [PubMed]

57. Schultz, T.F.; Kiyosue, T.; Yanovsky, M.; Wada, M.; Kay, S.A. A Role for LKP2 in the Circadian Clock of Arabidopsis. Plant Cell 2001, 13, 2659. [CrossRef] [PubMed]

58. Arite, T.; Iwata, H.; Ohshima, K.; Maekawa, M.; Nakajima, M.; Kojima, M.; Sakakibara, H.; Kyozuka, J. DWARF10, an RMS1/MAX4/DAD1 ortholog, controls lateral bud outgrowth in rice. Plant J. 2007, 51, 1019-1029. [CrossRef]

59. Hind, S.R.; Strickler, S.R.; Boyle, P.C.; Dunham, D.M.; Bao, Z.; Dohery, O.I.M.; Baccile, J.A.; Hoki, J.S.; Viox, E.G.; Clarke, C.R.; et al. Tomato receptor FLAGELLIN-SENSING 3 binds flgII-28 and activates the plant immune system. Nat. Plants 2016, 2, 6128. [CrossRef]

60. Katsuragi, Y.; Takai, R.; Furukawa, T.; Hirai, H.; Morimoto, T.; Katayama, T.; Murakami, T.; Che, F.-S. CD2-1, the C-Terminal Region of Flagellin, Modulates the Induction of Immune Responses in Rice. Mol. Plant Microbe Interact. 2015, $28,648-658$. [CrossRef]

61. Zipfel, C.; Kunze, G.; Chinchilla, D.; Caniard, A.; Jones, J.D.; Boller, T.; Felix, G. Perception of the Bacterial PAMP EF-Tu by the Receptor EFR Restricts Agrobacterium-Mediated Transformation. Cell 2006, 125, 749-760. [CrossRef]

62. Gomez, G.L.; Boller, T. FLS2: An LRR receptor-like kinase involved in the perception of the bacterial elicitor flagellin in Arabidopsis. Mol. Cell 2000, 5, 1003-1011. [CrossRef]

63. Buscaill, P.; Chandrasekar, B.; Sanguankiattichai, N.; Kourelis, J.; Kaschani, F.; Thomas, E.L.; Morimoto, K.; Kaiser, M.; Preston, G.M.; Ichinose, Y.; et al. Glycosidase and glycan polymorphism control hydrolytic release of immunogenic flagellin peptides. Science 2019, 364. [CrossRef]

64. Yamazaki, M.; Saito, K. Molecular Genetic Study on the Anthocyanin Chemotypes of Perilla frutescens var. crispa. Nat. Prod. Commun. 2011, 6, 423-427. [CrossRef] [PubMed]

65. Walker, A.R.; Davison, P.A.; Winfield, B.A.C.; James, C.M.; Srinivasan, N.; Blundell, T.L.; Esch, J.J.; Marks, M.D.; Gray, J.C. The TRANSPARENT TESTA GLABRA1 Locus, Which Regulates Trichome Differentiation and Anthocyanin Biosynthesis in Arabidopsis, Encodes a WD40 Repeat Protein. Plant Cell 1999, 11, 1337. [CrossRef] 
66. Sompornpailin, K.; Makita, Y.; Yamazaki, M.; Saito, K. A WD-repeat-containing putative regulatory protein in anthocyanin biosynthesis in Perilla frutescens. Plant Mol. Biol. 2002, 50, 485-495. [CrossRef]

67. Carey, C.C.; Strahle, J.T.; Selinger, D.A.; Chandler, V.L. Mutations in the pale aleurone color1 regulatory gene of the Zea mays anthocyanin pathway have distinct phenotypes relative to the functionally similar TRANSPARENT TESTA GLABRA1 gene in Arabidopsis thaliana. Plant Cell 2004, 16, 450-464. [CrossRef] [PubMed]

68. Kagaya, Y.; Nakamura, H.; Ejiri, S.I.; Tsutsumi, K.I.; Hidaka, S. The promoter from the rice nuclear gene encoding chloroplast aldolase confers mesophyll-specific and light-regulated expression in transgenic tobacco. Mol. Gen. Genet. 1995, 248, 668-674. [CrossRef]

69. Pang, Y.; Wenger, J.P.; Saathoff, K.; Peel, G.J.; Wen, J.; Huhman, D.; Allen, S.N.; Tang, Y.; Cheng, X.; Tadege, M.; et al. A WD40 Repeat Protein from Medicago truncatula Is Necessary for Tissue-Specific Anthocyanin and Proanthocyanidin Biosynthesis but Not for Trichome Development. Plant Physiol. 2009, 151, 1114-1129. [CrossRef]

70. Matus, J.T.; Poupin, M.J.; Cañón, P.; Bordeu, E.; Alcalde, J.A.; Arce-Johnson, P. Isolation of WDR and bHLH genes related to flavonoid synthesis in grapevine (Vitis vinifera L.). Plant Mol. Biol. 2010, 72, 607-620. [CrossRef]

71. Anderson, E.L.; Advani, V.R. Chloroplast and cytoplasmic enzymes: Three distinct isoenzymes associated with the reductive pentose phosphate cycle. Plant Physiol. 1970, 45, 583-585. [CrossRef] [PubMed]

72. Cho, Y.H.; Yoo, S.D. Signaling Role of Fructose Mediated by FINS1/FBP in Arabidopsis thaliana. PLoS Genet. 2011, 7, 1263. [CrossRef]

73. Gao, C.; Sheteiwy, M.S.; Han, J.; Dong, Z.; Pan, R.; Guan, Y.; Hamoud, Y.A.; Hu, J. Polyamine biosynthetic pathways and their relation with the cold tolerance of maize (Zea mays L.) seedlings. Plant Signal. Behav. 2020, 15, 7722. [CrossRef]

74. Yoon, Y.E.; Kuppusamy, S.; Cho, K.M.; Kim, P.J.; Kwack, Y.B.; Lee, Y.B. Influence of cold stress on contents of soluble sugars, vitamin $\mathrm{C}$ and free amino acids in-cluding gamma-aminobutyric acid (GABA) in spinach (Spinacia oleracea). Food Chem. 2017, 215, 185-192. [CrossRef]

75. Guo, X.; Zhang, L.; Dong, G.; Xu, Z.; Li, G.; Liu, N.; Wang, A.; Zhu, J. A novel cold-regulated protein isolated from Saussurea involucrata confers cold and drought tolerance in transgenic tobacco (Nicotiana tabacum). Plant Sci. 2019, 289, 246. [CrossRef]

76. Liu, X. Model assessment of nutrient removal via planting Sesuvium portulacastrum in floating beds in eu-trophic marine waters: The case of aquaculture areas of Dongshan Bay. Acta Oceanol. Sin. 2019, 38, 91-100.

77. Cai, B.; Li, Q.; Xu, Y.; Yang, L.; Bi, H.; Ai, X. Genome-wide analysis of the fructose 1,6-bisphosphate aldolase (FBA) gene family and functional characterization of FBA7 in tomato. Plant Physiol. Biochem. 2016, 108, 251-265. [CrossRef] [PubMed]

78. Menkens, A.E.; Schindler, U.; Cashmore, A.R. The G-box: A ubiquitous regulatory DNA element in plants bound by the GBF family of bZIP proteins. Trends Biochem. Sci. 1995, 20, 506-510. [CrossRef]

79. Fujita, Y.; Fujita, M.; Satoh, R.; Maruyama, K.; Parvez, M.M.; Seki, M.; Hiratsu, K.; Takagi, O.M.; Shinozaki, K.; Shinozaki, Y.K. AREB1 Is a Transcription Activator of Novel ABRE-Dependent ABA Signaling That Enhances Drought Stress Tolerance in Arabidopsis. Plant Cell 2005, 17, 3470-3488. [CrossRef]

80. Zhao, X.; Hao, W. LTR_FINDER: An efficient tool for the prediction of full-length LTR retrotransposons. Nucleic Acids Res. 2007, $35,265-268$. 